\title{
Changes in T lymphocyte subsets and intracellular cytokines after transfer of chemically extracted acellular nerve allografts
}

\author{
WEI LI ${ }^{1}$, WEN-WEN WU ${ }^{2}$, XING-SHI LIN ${ }^{3}$, SHU-XUN HOU ${ }^{2}$, HONG-BIN ZHONG ${ }^{2}$ and DI-KE RUAN ${ }^{1}$ \\ ${ }^{1}$ Department of Orthopaedics, Navy General Hospital, Beijing 100037; Departments of \\ ${ }^{2}$ Orthopaedics, and ${ }^{3}$ Immunity, PLA General Hospital, Beijing 100853, P.R. China
}

Received October 10, 2011; Accepted December 27, 2011

DOI: $10.3892 / \mathrm{mmr} .2012 .747$

\begin{abstract}
The aim of the present study was to observe the immune mechanism underlying the rejection of chemically extracted acellular nerve allografts for use in clinical applications. A total of $128 \mathrm{BALB} / \mathrm{c}$ mice were randomly divided into a negative contrast group (NC, 32 mice), a fresh autograft group (AG, 32 mice), a fresh allogeneic nerve group (FN, 32 mice) and a chemically extracted acellular allogeneic nerve group (CEN, 32 mice). Various types of nerve grafts were implanted into the thigh muscle of $\mathrm{BALB} / \mathrm{C}$ mice in the corresponding groups. At 3, 7, 14 and 28 days post-operation, the mice ( 8 cases from each group) were sacrificed and their spleens were extracted. The spleens were ground into paste. The erythrocytes and other cells were lysed using distilled water and the T lymphocytes were collected. Monoclonal antibodies (CD3, CD4, CD8, CD25, IL-2, IFN- $\gamma$ and TNF- $\alpha$ ) were then added to the solution. The Facial Action Coding System was used to determine the positive rates of the cells combined with the monoclonal antibodies above. No significant statistical differences were observed between the CEN, NC and AG groups. However, some data of the FN group were significantly higher than those of the other groups at the corresponding time. No obvious immune rejections were observed among the chemically extracted acellular nerve allografts compared with fresh nerve autograft.
\end{abstract}

\section{Introduction}

Peripheral nerve repair is one of the challenges of clinical practice. Most patients prefer the use of autologous nerve grafts to repair peripheral nerve defects. However, available nerve sources for autologous transplantation are limited.

Correspondence to: $\mathrm{Dr}$ Wei Li, Department of Orthopaedics, Navy General Hospital, Beijing 100037, P.R. China

E-mail: weilichn@126.com

Key words: peripheral nerve, nerve graft, T lymphocyte subsets, lymphokines, immunity
Immune rejection from the use of other nerves has not been effectively addressed as well. After discontinuation of immunosuppressive agents, heterogeneous nerve-transplanted Schwann cells exhibit rejection. Subsequent studies have confirmed the immunogenicity of Schwann cells (1), which show transplant immune rejection $(2,3)$. Cell factors are the most important components of allogeneic nerve-transplanted antigens, followed by the myelin sheath; the levels of antigens of the collagen and extracellular matrix, including Schwann cell basal lamina, are very low (4). Schwann cells are antigenpresenting cells, which have the ability to synthesize, transfer and express major histocompatibility complex class II (MHC II) antigens and release cytokines (e.g., IL-2). Cytokines are essential materials that induce $\mathrm{T}$ cells to differentiate. Many Schwann cell surfaces in vivo can express MHC II, which also supports this theory (5-7).

When adult Schwann cells are co-cultured with sensitive T cells, they express MHC II antigens; this indicates that cultured adult Schwann cells handle and process the integrity antigen and the antigen presented to $\mathrm{T}$ lymphocytes (8). MHC II expression mainly occurs on the cell membrane and in Schwann cells, which confirms that Schwann cells are antigen-presenting cells. Experimental evidence also shows that peripheral nerve Schwann cells are the main antigenpresenting cells (9-12). The allogeneic nerve transplanted in endothelial cells and macrophages are also antigen-presenting cells (13). A certain amount of MHC II expression is present in endothelial cells subjected to immune rejection (14). Immune effector cells and immune molecules act on endothelial cells (15).

When chemical digestion is used to treat allogeneic nerve grafts (16), the main histocompatibility complex antigens within the aforementioned neural stem and the myelin sheath can be effectively removed, greatly reducing immunogenicity and preventing rejection. Simultaneously, the neural tube membrane and the lamellar structure are retained, providing a good networks for nerve fiber regeneration.

Although allograft nerves are generally considered significantly less antigenic after chemical treatment, corresponding system studies have been not reported. To confirm the safety of the clinical application and the feasibility of the method, T-lymphocyte subsets were studied after chemically extracted 
Table I. Comparison of T lymphocytes and activated T lymphocytes 3 days after surgery in all the experimental groups.

\begin{tabular}{lcccrrr}
\hline & NC & AG & FN & CEN & F-value & P-value \\
\hline $\mathrm{CD}^{+}(\%)$ & $70.22 \pm 3.24$ & $69.55 \pm 2.34$ & $70.79 \pm 3.62$ & $70.25 \pm 2.35$ & 0.44 & 0.82 \\
$\mathrm{CD}^{+}(\%)$ & $40.23 \pm 1.85$ & $38.89 \pm 2.93$ & $40.47 \pm 2.40$ & $40.15 \pm 2.42$ & 1.03 & 0.41 \\
$\mathrm{CD}^{+}(\%)$ & $20.31 \pm 3.54$ & $21.61 \pm 1.92$ & $22.03 \pm 1.78$ & $21.75 \pm 2.33$ & 0.66 & 0.66 \\
$\mathrm{CD} 25^{+}(\%)$ & $3.19 \pm 0.87$ & $3.46 \pm 0.85$ & $3.22 \pm 0.98$ & $3.34 \pm 0.77$ & 0.22 & 0.95
\end{tabular}

NC, sham operation group; AG, fresh autograft group; FN, fresh allogeneic nerve group; CEN, chemically extracted acellular allogeneic nerve group. For the indicators of the same treatment group, the LSD-t test was used; no significant differences were noted between each treatment group. Values represent mean $\pm \mathrm{SD}$.

Table II. Comparison of T lymphocytes and activated T lymphocytes 7 days after surgery in all the experimental groups.

\begin{tabular}{|c|c|c|c|c|c|c|}
\hline & $\mathrm{NC}$ & $\mathrm{AG}$ & FN & CEN & F-value & P-value \\
\hline $\mathrm{CD}^{+}(\%)$ & $71.82 \pm 3.17$ & $73.14 \pm 2.73$ & $75.21 \pm 4.08$ & $73.32 \pm 3.11$ & 1.15 & 0.35 \\
\hline $\mathrm{CD}^{+}(\%)$ & $40.69 \pm 3.29$ & $41.05 \pm 2.59$ & $44.06 \pm 3.40$ & $41.35 \pm 2.23$ & 1.61 & 0.18 \\
\hline $\mathrm{CD}^{+}(\%)$ & $21.98 \pm 1.93$ & $22.96 \pm 3.64$ & $24.19 \pm 3.36$ & $24.32 \pm 2.60$ & 0.80 & 0.56 \\
\hline $\mathrm{CD} 25^{+}(\%)$ & $3.16 \pm 0.96$ & $3.46 \pm 0.83$ & $5.75 \pm 0.83^{\mathrm{a}, \mathrm{b}}$ & $4.26 \pm 1.32$ & 15.02 & $<0.01$ \\
\hline
\end{tabular}

NC, sham operation group; AG, fresh autograft group; FN, fresh allogeneic nerve group; CEN, chemically extracted acellular allogeneic nerve group. ${ }^{\mathrm{a} C}$ Comparison of the FN group and $\mathrm{NC}$ group $(\mathrm{t}=-5.7725, \mathrm{P}<0.05)$; ${ }^{\mathrm{b}}$ comparison of the FN group and $\mathrm{AG}$ group $(\mathrm{t}=-5.5181, \mathrm{P}<0.05)$. Values represent mean $\pm \mathrm{SD}$.

allograft nerve grafts were transplanted, as well as changes in activated T cells and cytokine expression to obtain an immunologic basis for clinical application.

\section{Materials and methods}

Preparation of transplated nerves. A total of 16 healthy 6-week-old C57BL/6 mice weighing 18-22 g were purchased from the Experimental Animal Center of PLA General Hospital. The sciatic nerve, $0.3 \mathrm{~mm}$ in diameter and $1.2 \mathrm{~cm}$ long, was bilaterally harvested from the mice. Using the improved Sondell method (17) for nerve chemical extraction, the donor nerve was treated by a chemical extraction process, and then placed in sterile phosphate-buffered saline solution and stored at $4^{\circ} \mathrm{C}$.

Animal models. Up to 128 healthy 6-week-old BALB/C mice (provided by the Experimental Animal Center of PLA General Hospital) weighing 18-22 g were randomly divided into 4 groups $(n=32)$ as follows: NC, sham operation group (negative control group); AG, fresh autograft group; FN, fresh allogeneic nerve group; and CEN, chemically extracted acellular allogeneic nerve group. The mouse femoral nerve that corresponds to each group was embedded within the muscle gap. The sham operation group served as the control. In the AG group, fresh sciatic nerves $0.3 \mathrm{~mm}$ in diameter and $1.2 \mathrm{~cm}$ long that were harvested and cut on the operation day from the BALB/c mice were transplanted. Fresh sciatic nerves from the C57BL/6 mice, $0.3 \mathrm{~mm}$ in diameter and $1.2 \mathrm{~cm}$ long, were transplanted in the FN group. Chemically pretreated C57BL/6 mouse sciatic nerves were transplanted in the CEN group.
Sixteen 6-week-old BALB/c mice and 16 C57BL/6 mice served as the corresponding donors for the nerve transplants of the AG and the FN group. The mice were randomly assigned and the nerves were transplanted within 1 day.

Experimental index. The animals were sacrificed after 3, 7, 14 and 28 days. The mice in each group were sacrificed by cervical dislocation at each time point (4 groups at each time point, all 32 mice) and then soaked in $75 \%$ ethanol for 5 min. The spleen was cleaned, placed in a Petri dish and washed with normal saline (NS; $0.9 \%$ saline solution). Up to $5 \mathrm{ml}$ of NS was added to each Petri dish and a 200-mesh stainless steel sieve was subsequently immersed. The spleens of the mice were placed on the steel sieve and then ground with the plunger of a 5-ml syringe. The spleen cell suspension was placed in a 50-ml glass centrifuge tube and centrifuged at $1500 \mathrm{rpm}$ for $8 \mathrm{~min}$. The supernatant was aspirated, the sediment was loosened, and then, $20 \mathrm{ml}$ of injection water was added and mixed rapidly for $15 \mathrm{~min}$. This was followed by $2 \mathrm{ml}$ of $10 \%$ sodium chloride solution, and mixed with small amounts of $0.9 \%$ NS. The mixture was centrifuged at $1,500 \mathrm{rpm}$ for $8 \mathrm{~min}$. The resulting pellet was then rinsed with $0.9 \%$ NS and then centrifuged for another $8 \mathrm{~min}$. A small amount of lymphocyte suspension was taken from the cell suspension liquid, dyed with trypan blue, placed on a plate and counted. Based on the count of each tube, the extracted cell suspension was added to each tube to adjust the lymphocytes to $1 \times 10^{6} /$ tube. Each Eppendorf tube was marked and then centrifuged at 3,000 rpm for $3 \mathrm{~min}$. Fluorescence-labeled antibodies (5 $\mu \mathrm{l}$ each tube; CD3, CD4, CD8, CD25, IL-2, IFN- $\gamma$, TNF- $\alpha$ monoclonal antibodies) were added to the corresponding labeled Eppendorf tubes and were 
Table III. Comparison of T lymphocytes and activated T lymphocytes 14 days after surgery in all the experimental groups.

\begin{tabular}{lccccrr}
\hline & NC & AG & FN & CEN & F-value & P-value \\
\hline $\mathrm{CD}^{+}(\%)$ & $68.06 \pm 2.76$ & $68.67 \pm 1.78$ & $72.08 \pm 2.00^{\mathrm{a}}$ & $68.98 \pm 1.29$ & 9.26 & $<0.01$ \\
$\mathrm{CD}^{+}(\%)$ & $36.06 \pm 2.87$ & $35.86 \pm 3.28$ & $42.15 \pm 2.47^{\mathrm{b}-\mathrm{d}}$ & $36.43 \pm 1.56$ & 12.87 & $<0.01$ \\
$\mathrm{CD}^{+}(\%)$ & $17.34 \pm 4.03$ & $18.25 \pm 1.44$ & $22.82 \pm 2.45^{\mathrm{e}-\mathrm{g}}$ & $18.58 \pm 1.60$ & 9.06 & $<0.01$ \\
$\mathrm{CD} 25^{+}(\%)$ & $3.80 \pm 1.07$ & $4.67 \pm 2.18$ & $9.18 \pm 1.69^{\mathrm{h}-\mathrm{j}}$ & $4.44 \pm 1.13$ & 25.94 & $<0.01$ \\
\hline
\end{tabular}

$\mathrm{NC}$, sham operation group; AG, fresh autograft group; FN, fresh allogeneic nerve group; CEN, chemically extracted acellular allogeneic nerve group. ${ }^{a}$ Comparison of FN group and $\mathrm{NC}$ group $(\mathrm{t}=-3.3359, \mathrm{P}<0.05) ;{ }^{\mathrm{b}}$ comparison of $\mathrm{FN}$ group and $\mathrm{NC}$ group $(\mathrm{t}=-4.5491, \mathrm{P}<0.01) ;{ }^{\mathrm{c}} \mathrm{comparison}$ of FN group and AG group ( $\mathrm{t}=-4.3329, \mathrm{P}<0.01)$; ${ }^{\mathrm{d}}$ comparison of $\mathrm{FN}$ group and $\mathrm{CEN}$ group $(\mathrm{t}=-5.5380, \mathrm{P}<0.01)$; ${ }^{\mathrm{e}}$ comparison of $\mathrm{FN}$ group and NC group $(\mathrm{t}=-3.2864, \mathrm{P}<0.01)$; ${ }^{\mathrm{f}}$ comparison of FN group and AG group $(\mathrm{t}=-4.5484, \mathrm{P}<0.05)$; ${ }^{\mathrm{g}}$ comparison of FN group and CEN group ( $\mathrm{t}=-4.0984, \mathrm{P}<0.05)$; ${ }^{\mathrm{h}}$ comparison of $\mathrm{FN}$ group and $\mathrm{NC}$ group $(\mathrm{t}=-7.6075, \mathrm{P}<0.01)$; ${ }^{\mathrm{i}}$ comparison of $\mathrm{FN}$ group and $\mathrm{AG}$ group $(\mathrm{t}=-4.6246$, $\mathrm{P}<0.01) ;{ }^{\mathrm{j}}$ comparison of $\mathrm{FN}$ group and $\mathrm{CEN}$ group $(\mathrm{t}=-6.5946, \mathrm{P}<0.01)$. Values represent mean $\pm \mathrm{SD}$.

Table IV. Comparison of T lymphocytes and activated T lymphocytes 28 days after surgery in all the experimental groups.

\begin{tabular}{|c|c|c|c|c|c|c|}
\hline & $\mathrm{NC}$ & $\mathrm{AG}$ & $\mathrm{FN}$ & CEN & F-value & P-value \\
\hline $\mathrm{CD}^{+}(\%)$ & $63.12 \pm 3.25$ & $63.56 \pm 3.42$ & $69.31 \pm 1.91^{\mathrm{a}-\mathrm{c}}$ & $64.06 \pm 2.09$ & 10.64 & $<0.01$ \\
\hline $\mathrm{CD}^{+}(\%)$ & $33.42 \pm 3.11$ & $33.73 \pm 2.90$ & $40.92 \pm 3.22^{\mathrm{d}-\mathrm{f}}$ & $33.95 \pm 3.26$ & 11.44 & $<0.01$ \\
\hline $\mathrm{CD}^{+}(\%)$ & $15.27 \pm 1.92$ & $14.05 \pm 2.14$ & $16.44 \pm 1.28$ & $15.53 \pm 2.14$ & 8.92 & $<0.01$ \\
\hline $\mathrm{CD} 25^{+}(\%)$ & $3.83 \pm 1.32$ & $3.87 \pm 1.15$ & $8.30 \pm 0.98^{\mathrm{g}-\mathrm{i}}$ & $5.00 \pm 1.47$ & 23.83 & $<0.01$ \\
\hline
\end{tabular}

$\mathrm{NC}$, sham operation group; AG, fresh autograft group; FN, fresh allogeneic nerve group; CEN, chemically extracted acellular allogeneic nerve group. ${ }^{a}$ Comparison of FN group and $\mathrm{NC}$ group $(\mathrm{t}=-4.6444, \mathrm{P}<0.01) ;{ }^{\mathrm{b}}$ comparison of $\mathrm{FN}$ group and $\mathrm{AG}$ group $(\mathrm{t}=-4.1518, \mathrm{P}<0.01)$; ${ }^{\mathrm{c}} \mathrm{comparison}$ of FN group and CEN group ( $\mathrm{t}=-5.2447, \mathrm{P}<0.05) ;{ }^{\mathrm{d}}$ comparison of $\mathrm{FN}$ group and $\mathrm{NC}$ group $(\mathrm{t}=-4.7386, \mathrm{P}<0.01) ;{ }^{\mathrm{e}}$ comparison of $\mathrm{FN}$ group and $\mathrm{AG}$ group $(\mathrm{t}=-4.1518, \mathrm{P}<0.01)$; ${ }^{\mathrm{f}} \mathrm{Comparison}$ of $\mathrm{FN}$ group and $\mathrm{CEN}$ group $(\mathrm{t}=-4.3024, \mathrm{P}<0.05)$; ${ }^{\mathrm{g}}$ comparison of $\mathrm{FN}$ group and $\mathrm{NC}$ group $(\mathrm{t}=-7.6903$, $\mathrm{P}<0.01)$; ${ }^{\mathrm{h}}$ comparison of $\mathrm{FN}$ group and AG group $(\mathrm{t}=-8.2929, \mathrm{P}<0.01)$; ${ }^{\mathrm{i}}$ comparison of FN group and CEN group $(\mathrm{t}=-5.2831, \mathrm{P}<0.01)$. Values represent mean $\pm \mathrm{SD}$.

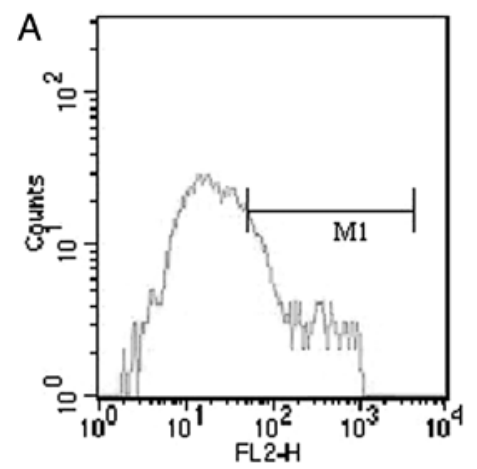

Histogram Statistics

\begin{tabular}{|c|c|c|c|}
\hline \multicolumn{2}{|c|}{ File: Ixs12.566 } & \multicolumn{2}{|c|}{ Gate: G1 } \\
\hline Marker & Events & \% Gated & Mean \\
\hline All & 5827 & 100.00 & 73.50 \\
\hline M1 & 1230 & 21.11 & 271.89 \\
\hline
\end{tabular}

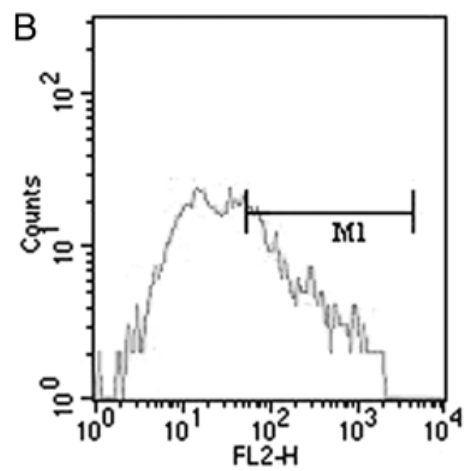

Histogram Statistics

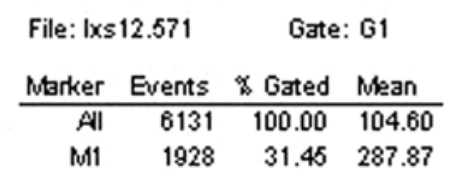

Figure 1. Counts of CD25+ $\mathrm{T}$ lymphocytes 14 days after surgery; (A) CEN group, (B) FN group.

mixed thoroughly; one was left as the negative control. Each tube was placed in the dark at $4^{\circ} \mathrm{C}$ for $30 \mathrm{~min}$. The excess fluorescent antibodies were then washed and the solution was fixed with $2 \%$ paraformaldehyde for flow cytometry. Up to
10,000 lymphocytes were counted in each labeled Eppendorf tube. The $\mathrm{T}$ cell subsets, activated $\mathrm{T}$ cells and the percentage of lymphocytes expressing IL-2, IFN- $\gamma$ and TNF- $\alpha$ were analyzed with CellQuest ${ }^{\mathrm{TM}}$ software. 
A

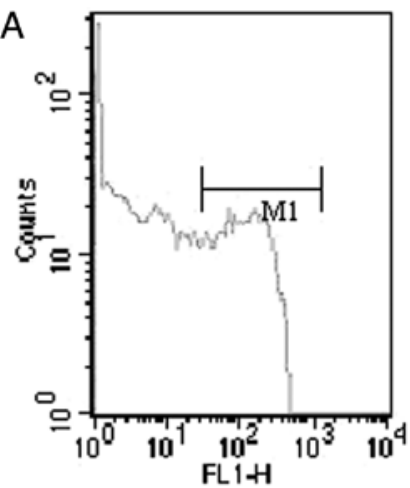

Histogram Statistics

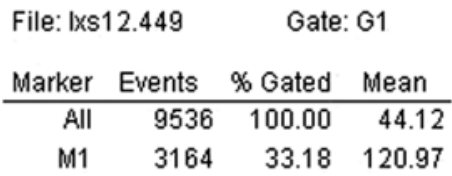

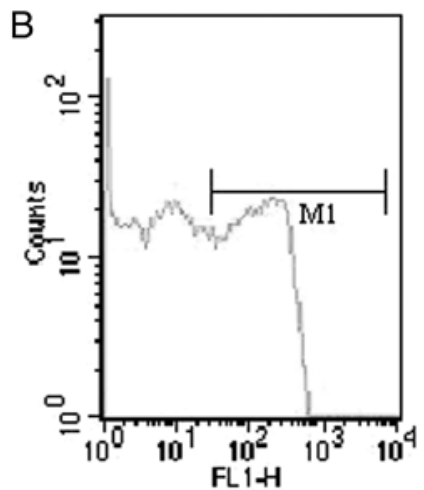

Histogram Statistics

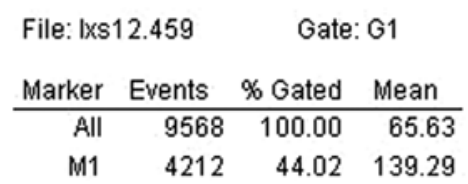

Figure 2. Counts of $\mathrm{CD}^{+} \mathrm{T}$ lymphocytes 14 days after surgery; (A) CEN group, (B) FN group.

Table V. Comparison of intracellular cytokine expression in all experimental groups 3 days after surgery.

\begin{tabular}{lrrrrrr}
\hline & \multicolumn{1}{c}{ NC } & \multicolumn{1}{c}{ AG } & FN & CEN & F-value & P-value \\
\hline IL-2 (\%) & $10.08 \pm 2.59$ & $9.88 \pm 1.82$ & $10.62 \pm 2.40$ & $12.00 \pm 2.03$ & 0.93 & 0.47 \\
IFN- $\gamma(\%)$ & $15.61 \pm 2.96$ & $16.70 \pm 2.29$ & $16.03 \pm 1.86$ & $16.45 \pm 2.83$ & 0.33 & 0.89 \\
TNF- $\alpha(\%)$ & $9.89 \pm 1.61$ & $10.86 \pm 2.59$ & $11.74 \pm 2.56$ & $10.89 \pm 1.95$ & 0.75 & 0.59 \\
\hline
\end{tabular}

NC, sham operation group; AG, fresh autograft group; FN, fresh allogeneic nerve group; CEN, chemically extracted acellular allogeneic nerve group. For the indicators of the same treatment group, the LSD-t test was used; no significant differences were noted between each treatment group. Values represent mean $\pm \mathrm{SD}$.

Table VI. Comparison of intracellular cytokine expression in all experimental groups 7 days after surgery.

\begin{tabular}{lcccccr}
\hline & NC & AG & FN & CEN & F-value & P-value \\
\hline IL-2 (\%) & $18.25 \pm 3.34$ & $21.00 \pm 2.78$ & $21.02 \pm 2.45$ & $23.45 \pm 2.64$ & 3.12 & 0.02 \\
IFN- $\gamma(\%)$ & $24.56 \pm 3.44$ & $23.33 \pm 3.49$ & $24.82 \pm 4.71$ & $24.42 \pm 23.57$ & 0.23 & 0.95 \\
TNF- $\alpha(\%)$ & $15.18 \pm 3.05$ & $15.94 \pm 2.13$ & $16.42 \pm 1.74$ & $16.46 \pm 2.05$ & 0.54 & 0.75 \\
\hline
\end{tabular}

$\mathrm{NC}$, sham operation group; AG, fresh autograft group; FN, fresh allogeneic nerve group; CEN, chemically extracted acellular allogeneic nerve group. For the indicators of the same treatment group, the LSD-t test was used; no significant differences were noted between each treatment group. Values represent mean $\pm \mathrm{SD}$.

Statistical analysis. The data were analyzed using Stata7.0 statistical software for single-factor ANOVA. Pairwise comparison between each group was analyzed by the paired $\mathrm{t}$-test, and mean $\pm \mathrm{SD}$ represents the average value. $\mathrm{P}<0.05$ was considered statistically significant.

\section{Results}

General data. Three mice died because of anesthesia, as well as intra-operative and post-operative bleeding during the experiments. The others survived. The mice gained consciousness $0.5-2.0 \mathrm{~h}$ after the operation. They were less active and exhibited poor feeding within 24-48 $\mathrm{h}$. The surgical site of the mice swelled within 36-48 $\mathrm{h}$ after the surgery, but no bleeding wounds and exudates were present and all the mice regained their normal gait after 3 days.

Activation of cell subsets and T cells. The percentages of $\mathrm{T}$ lymphocyte subsets and activated $\mathrm{T}$ lymphocytes detected by flow cytometry at different time points are shown in 
Table VII. Comparison of intracellular cytokine expression in all experimental groups 14 days after surgery.

\begin{tabular}{lcccccc}
\hline & NC & AG & FN & CEN & F-value & P-value \\
\hline IL-2 $(\%)$ & $17.62 \pm 1.98$ & $17.19 \pm 2.52$ & $22.06 \pm 2.67^{\mathrm{a}, \mathrm{b}}$ & $19.02 \pm 1.86$ & 8.49 & $<0.01$ \\
$\mathrm{IFN}-\gamma(\%)$ & $17.15 \pm 1.79$ & $17.32 \pm 1.43$ & $20.70 \pm 1.89^{\mathrm{c}, \mathrm{d}}$ & $18.19 \pm 1.85$ & 8.34 \\
TNF- $\alpha(\%)$ & $14.80 \pm 1.91$ & $15.46 \pm 2.73$ & $15.08 \pm 1.75$ & $15.46 \pm 1.89$ & 0.52 & $<0.01$ \\
\hline
\end{tabular}

NC, sham operation group; AG, fresh autograft group; FN, fresh allogeneic nerve group; CEN, chemically extracted acellular allogeneic nerve group. ${ }^{\mathrm{a} C o m p a r i s o n}$ of $\mathrm{FN}$ group and $\mathrm{NC}$ group $(\mathrm{t}=-3.7780, \mathrm{P}<0.05) ;{ }^{\mathrm{b}}$ comparison of $\mathrm{FN}$ group and AG group $(\mathrm{t}=-3.7518, \mathrm{P}<0.01) ;{ }^{\mathrm{c}} \mathrm{comparison}$ of FN group and $\mathrm{NC}$ group $(\mathrm{t}=-3.8573, \mathrm{P}<0.05)$; ${ }^{\mathrm{d}}$ comparison of $\mathrm{FN}$ group and $\mathrm{AG}$ group $(\mathrm{t}=-4.0338, \mathrm{P}<0.05)$. Values represent mean $\pm \mathrm{SD}$.

Table VIII. Comparison of intracellular cytokine expression in all experimental groups 28 days after surgery.

\begin{tabular}{lcccrrr}
\hline & NC & AG & FN & CEN & F-value & P-value \\
\hline IL-2 $(\%)$ & $12.45 \pm 2.49$ & $11.96 \pm 1.55$ & $16.69 \pm 2.60^{\mathrm{a}-\mathrm{c}}$ & $12.71 \pm 1.40$ & 10.82 \\
IFN- $\gamma(\%)$ & $14.98 \pm 1.48$ & $14.61 \pm 0.94$ & $17.91 \pm 1.70^{\mathrm{d}-\mathrm{f}}$ & $14.04 \pm 1.59$ & 12.44 & $<0.01$ \\
TNF- $\alpha(\%)$ & $11.50 \pm 1.46$ & $12.29 \pm 2.44$ & $10.96 \pm 1.44$ & $11.62 \pm 1.58$ & 1.14 & 0.36 \\
\hline
\end{tabular}

$\mathrm{NC}$, sham operation group; AG, fresh autograft group; FN, fresh allogeneic nerve group; CEN, chemically extracted acellular allogeneic nerve group. ${ }^{\mathrm{a} C o m p a r i s o n}$ of FN group and $\mathrm{NC}$ group $(\mathrm{t}=-3.3312, \mathrm{P}<0.05) ;{ }^{\mathrm{b}}$ comparison of FN group and AG group $(\mathrm{t}=-4.4198, \mathrm{P}<0.01) ;{ }^{\mathrm{c}} \mathrm{comparison}$ of FN group and CEN group ( $\mathrm{t}=-3.8121, \mathrm{P}<0.05)$; ${ }^{\mathrm{d}}$ comparison of $\mathrm{FN}$ group and $\mathrm{NC}$ group $(\mathrm{t}=-3.6767, \mathrm{P}<0.05)$; ${ }^{\mathrm{e}}$ comparison of $\mathrm{FN}$ group and AG group $(\mathrm{t}=-4.8049, \mathrm{P}<0.01) ;{ }^{\mathrm{f}}$ comparison of $\mathrm{FN}$ group and $\mathrm{CEN}$ group $(\mathrm{t}=-4.7025, \mathrm{P}<0.01)$. Values represent mean $\pm \mathrm{SD}$.

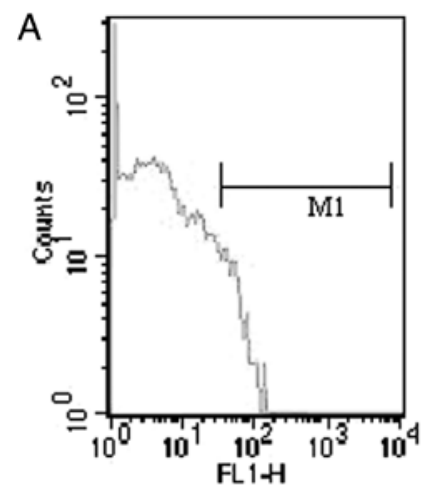

Histogram Statistics

\begin{tabular}{rrrr}
\multicolumn{2}{c}{ File: Ixs12.506 } & \multicolumn{3}{c}{ Gate: G1 } \\
& & M Gated & Mean \\
Marker & Events & \% Gan \\
\hline All & 9801 & 100.00 & 8.93 \\
M1 & 581 & 5.93 & 59.31
\end{tabular}

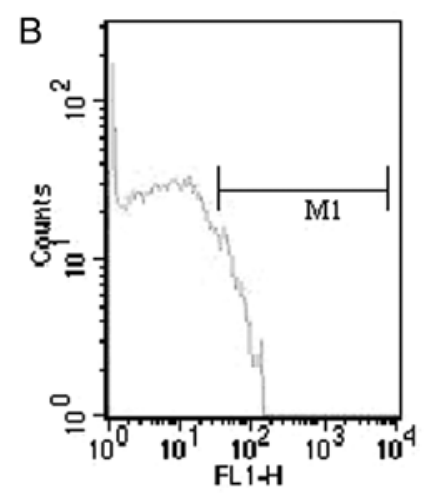

Histogram Statistics

\begin{tabular}{l} 
File: Ixs12.648 \\
\multicolumn{3}{c}{ Gate: G1 } \\
\begin{tabular}{rrrr} 
Marker & Events & \% Gated & Mean \\
\hline All & 9385 & 100.00 & 12.80 \\
M1 & 825 & 8.79 & 64.52
\end{tabular}
\end{tabular}

Figure 3. Counts of cells expressing IFN- $\gamma 14$ days after surgery; (A) CEN group, (B) FN group.

Tables I-IV. The counts of CD25+ $\mathrm{T}$ lymphocytes 14 days after surgery by flow cytometry in the CEN group is shown in Fig. 1A. The FN group is shown in Fig. 1B. The counts of $\mathrm{CD}^{+} \mathrm{T}$ lymphocytes 14 days after surgery by flow cytometry in the CEN group is shown in Fig. 2A. The FN group is shown in Fig. 2B.

Intracellular cytokines. The intracellular cytokine expression levels detected by flow cytometry at various time points are shown in Tables V-VIII. The counts of cells expressing IFN- $\gamma$
14 days after surgery by flow cytometry in the CEN group is shown in Fig. 3A. The FN group is shown in Fig. 3B. The counts of cells expressing IL-2 14 days after surgery by flow cytometry in the CEN group is shown in Fig. 4A. FN group is shown in Fig. 4B.

\section{Discussion}

Changes and cell types in lymphocyte subsets in the body as well as cytokine levels reflect the immune status of transplant 


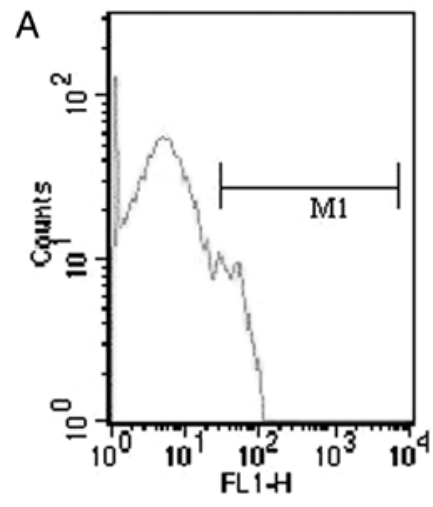

Histogram Statistics

\begin{tabular}{|c|c|c|c|}
\hline \multicolumn{2}{|c|}{ File: Ixs12.246 } & \multicolumn{2}{|c|}{ Gate: G1 } \\
\hline Marker & Events & $\%$ Gated & Mean \\
\hline All & 9517 & 100.00 & 8.85 \\
\hline M1 & 610 & 6.41 & 50.14 \\
\hline
\end{tabular}

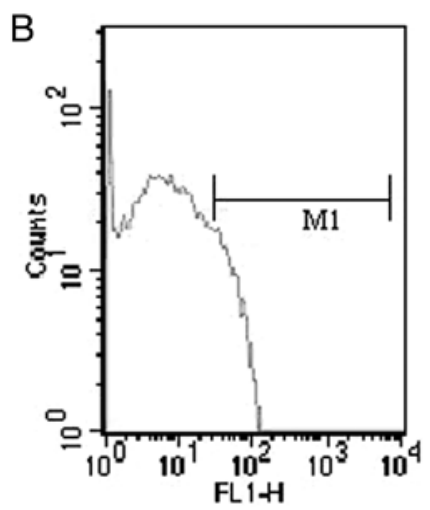

Histogram Statistics

\begin{tabular}{l} 
File: Ixs12.620 \\
\multicolumn{3}{c}{ Gate: G1 } \\
\begin{tabular}{rrrr} 
Marker & Events & \% Gated & Mean \\
\hline All & 9611 & 100.00 & 11.49 \\
M1 & 921 & 9.58 & 48.26
\end{tabular}
\end{tabular}

Figure 4. Counts of cells expressing IL-2 14 days after surgery; (A) CEN group, (B) FN group.

rejection and are sensitive indicators. In the body, MHC II antigens on the surface of most nucleated cells have been identified as $\mathrm{CD}^{+}$. The MHC II antigen expressed in B lymphocytes, monocytes, macrophages, dendritic cells and vascular endothelial and ductal epithelial cells, which are $\mathrm{T}$ lymphocyte antigen-presenting cells have been identified as $\mathrm{CD}^{+}{ }^{+} \mathrm{T}$ cells. All mature $\mathrm{T}$ cell surfaces express the $\mathrm{CD}^{+}$ antigen. The ability of $\mathrm{T}$ cells to recognize foreign antigens depends mainly on the $\mathrm{T}$ cell receptor, CD25 ${ }^{+}$(soluble interleukin- 2 receptor $\alpha$ chain), the activated $\mathrm{T}$ cell antigen, which is a sensitive indicator for transplant rejection (18).

Acute rejection generally occurs within one week to six months after transplantation. The main form of immune response in allogeneic nerve transplants is cell-mediated immunity. Through direct or indirect activation of helper $\mathrm{T}$ cells, foreign antigens secrete cytokine IL-2 to activate CTL. IFN- $\gamma$ activates monocytes, whereas IL-1, IL-2 and IL-4 activate $B$ cells into plasma cells to produce specific antibodies and then attack the target cells, tissues and organs (4), which causes vascular endothelial cell damage. A series of intracellular cytokines (such as IL-2 and IFN- $\gamma$ ) released by helper T cells may reflect the immune status and transplant rejection (19). Sander et al established a detection method for intracellular cytokines at the single-cell level using paraformaldehyde saponin penetration after the use of indirect immunofluorescence (20).

In this experiment, $\mathrm{CD}^{+}, \mathrm{CD}^{+}$and $\mathrm{CD}^{+} \mathrm{T}$ cells in the chemically extracted peripheral nerve transplant cells (CEN group) showed no significant change by flow cytometry at 3-14 days and at 28 days after transplantation; similar to the sham operated group, the $\mathrm{CD}^{+}, \mathrm{CD}^{+}$and $\mathrm{CD}^{+}$expression rate in the autologous nerve transplant $(\mathrm{AG})$ group tended to decrease. In contrast, $\mathrm{CD} 25^{+}$expression at each time point from 3 to 28 days increased slightly. However, the $\mathrm{CD}^{+}, \mathrm{CD}^{+}, \mathrm{CD}^{+}$ and $\mathrm{CD} 25^{+}$expression at all time points showed no significant difference compared with the sham operated group and the autologous nerve transplanted (AG) group. In the fresh nerve transplanted (FN) group, the $\mathrm{T}$ cell expression rates of $\mathrm{CD}^{+}$, $\mathrm{CD}^{+}$and $\mathrm{CD}^{+}$at 3-14 days were significantly higher, which peaked at day 7 and decreased at 28 days.

The number of $\mathrm{CD} 25^{+} \mathrm{T}$ cells increased at all time points from 3 to 28 days and reached a peak at day 14. In the fresh nerve transplanted (FN) group, except for the $\mathrm{CD}^{+} \mathrm{T}$ cells, the rate during the period of 14-28 days was statistically significant $(\mathrm{P}<0.05)$ and the difference in the remaining indicators compared with the sham operation group and the autologous nerve transplanted (AG) group were statistically significant $(\mathrm{P}<0.01)$. Differences in the $\mathrm{CD} 25^{+} \mathrm{T}$ cell detection rate were statistically significant $(\mathrm{P}<0.01)$ between the fresh nerve transplanted (FN) group and the other three groups from 14 to 28 days. After the allogeneic peripheral nerves were treated by chemical extraction, the number of cells positive for IL- 2, IFN- $\gamma$ and TNF- $\alpha$ in the sham operation group and the autologous nerve transplanted (AG) group tended to increase, as shown by flow cytometry during the period of 3-14 days; a high level was reached within 7 days and eventually decreased at 28 days. In the fresh nerve transplanted (FN) group at 14 days, the IL-2 and IFN- $\gamma$ expression rates were significantly higher $(\mathrm{P}<0.05 ; \mathrm{P}<0.01)$ than those of the sham operation group and the autologous nerve transplanted (AG) group. At day 28 , the IL-2 and IFN- $\gamma$ expression rates were significantly higher in the FN group $(\mathrm{P}<0.05 ; \mathrm{P}<0.01)$ than those of the sham operation group, the nerve autograft (AG) group and the chemical acellular nerve allograft (CEN) group.

In conclusion, fresh peripheral nerve allograft rejection after transplantation follows an acute course. Chemical nerve extraction effectively removes the histocompatibility complex cells and myelin in the major nerve trunk, thereby reducing its immunogenicity and minimizing the risk of rejection. The use of chemicals to treat the cells significantly reduces antigenicity. Immunogenicity after the chemical treatment of the allogeneic nerve cells is equal to or close to that of autologous nerves and 
significantly lower than that of fresh nerve allografts. These findings confirm the feasibility and safety of the chemical extraction of peripheral nerve cells for clinical application.

\section{References}

1. Aguayo AJ, Mizuno K and Bray GM: Schwann cell transplantation: evidence for a primary sheath cell disorder causing hypomyelination in quaking mice. J Neuropath Exp Neurol 36: 595, 1977.

2. Aguayo AJ, Bray GM and Kasarjian J: Differences in myelination of mouse axons by transplanted human and mouse Schwann cells. Neurology 28: 356, 1978.

3. Aguayo AJ, Bray GM and Perkins SC: Axon-Schwann cell relationships in neuropathies of mutant mice. Ann NY Acad Sci 317 512-531, 1979.

4. Evans PJ, Midha R and Mackinnon SE: The peripheral nerve allograft: a comprehensive review of regeneration and neuroimmunology. Prog Neurobiol 43: 187-233, 1994.

5. Esiri ME and Reading MC: Macrophages, lymphocytes and major histocompatibility complex class II antigens in adult human sensory and sympathetic ganglia. Neurology 23: 187-193, 1989.

6. Scarpini E, Lisak RP, Beretta S, et al: Quantitative assessment of class II molecules in normal and pathological nerves. Brain 113: 659-675, 1990

7. Trumble $\mathrm{T}$ and Stanislaw J: Immunology of peripheral nerves and response to trauma. J Orthop Res 9: 367-373, 1991.

8. Bergsteinsdottir K, Kingston A and Iessen KR: Rat Schwann cells can be induced to express major histocompatibility complex class II molecules in vivo. J Neurocytol 21: 382-390, 1992.

9. Colson YL, Markus BH, Zeevi A and Duquesnoy RJ: Increased lymphocyte adherence to human arterial endothelial cell monolayers in the context of allorecognition. J Immunol 144: 2975-2984, 1990.
10. Hayry P, Renkonen R, Leszczynski D, et al: Local events in graft rejection. Transplant Proc 21: 3716-3720, 1989.

11. Rose ML, Page C, Hengstenberg C and Yacoub MH: Identification of antigen presenting cells in normal and transplanted human heart: importance of endothelial cells. Human Immunol 28: 179-185, 1990.

12. Turunen JP, Halttunen J, Häyry P and Renkonen R: Lymphocytes bind to capillary endothelium during heart allograft rejection. Transplant Proc 22: 126, 1990.

13. Yu LT, Hickey WF, Silvers WS, LaRossa D and Rostami AM: Expression of class II antigens on peripheral nerve allografts. Ann NY Acad Sci 540: 472-474, 1988.

14. Lassner F, Schaller E, Steinhoff G, et al: Cellular mechanisms of rejection and regeneration in peripheral nerve allografts. Transplantation 48: 386-392, 1989.

15. Pober JS and Cotran RS: The role of endothelial cells in inflammation. Transplantation 50: 537-544, 1990.

16. Sondell M, Lundborg G and Kanje M: Regeneration of the rat sciatic nerve into allografts acellular through chemical extraction. Brain Res 795: 44-54, 1998.

17. Aguayo AJ, Perkins SC and Bray GM: Persistence of abnormal myelination 4 months after transplantation of Schwann cells from trembler to normal mouse nerves. Neurology 27: 377, 1977.

18. Horowitz MC and Friedlaend GE: Immunologic aspects of bone transplantation. Orthop Clin North Am 18: 227, 1987.

19. Jung T, Schauer U, Heusser C, Neumann C and Rieger C: Detection of intracellular cytokines by flow cytometry. J Immunol Methods 159: 197-207, 1993.

20. Sander B, Andersson J and Andersson U: Assessment of cytokines by immunofluorescence and the paraformal dehyde-saponin procedure. Immunol Rev 119: 65-93, 1991. 